\title{
Etnogeomorfologia e paisagem
}

\author{
Ethnogeomorphology and landscape
}

LOPES $^{1}$, V. M.; RIBEIRO ${ }^{2}$, S.C.

wan.martins19@gmail.com

\begin{abstract}
Resumo
Relevo e paisagem se encontram visivelmente vinculados através de relações integradas e dinâmicas. A Etnogeomorfologia como novo campo de investigação, move esforços através da busca dos conhecimentos tradicionais sobre os aspectos geomorfológicos locais. Numa análise dos trabalhos etnogeomorfológicos já realizados, constatou-se que os conhecimentos não se limitam ao relevo e seus processos, mas abrange toda a teia de relações ambientais da paisagem. Assim a relação entre Etnogeomorfologia e Paisagem é claramente detectada através da descrição de uma série de processos geomorfológicos de maneira coerente, detalhada e integrada. Deste modo o principal objetivo deste trabalho é apontar que o conhecimento etnogeomorfológico que as comunidades locais possuem se encontra interligado aos demais elementos da paisagem, revelando assim que esses saberes não se encontram compartimentados, e se expandem muito além dos conhecimentos geomorfológicos propriamente ditos. Os trabalhos de Ribeiro (2012) e Lopes (2014) foram a base principal de análise, viabilizando a discussão aqui exposta.
\end{abstract}

Palavras-chave: Etnogeomorfologia, Paisagem, Visão Integrada.

\begin{abstract}
Relief and landscape are visibly connected through an integrated and dynamical relation. The Ethnogeomorphology, as a new field of investigation, works in order to find traditional knowledge about local geomorphological aspects. In an analysis of the ethnogeomorphological works already existent, it was able to find that the knowledge doesn't end in relief and its processes, but also goes through the whole net of environmental relations of the landscape. This way, the relation between Ethnogeomorphology and Landscape is clearly detected through the description of a series of coherent, detailed, and integrated geomorphological processes. With this being said, the most important role of this work is to point the Ethnogeomorphological knowledge that the local communities hold are interlaced by the other elements of the landscape, revealing that such learning isn't found compartmentalized, and are expanded much further from the properly said geomorphological knowledge. The researches of Ribeiro (2012) and Lopes (2014) were the most important basis for this analysis, making possible the discussions made here.
\end{abstract}

Keywords: Ethnogeomorphology, Landscape, Integrated Vision.

\section{INTRODUÇÃO}

A Etnogeomorfologia como novo campo de investigação, traz uma proposta muito desafiadora diante do que se vem sendo trabalhado na geomorfologia, através da busca dos conhecimentos tradicionais sobre os aspectos geomorfológicos locais. Relevo e paisagem se encontram visivelmente vinculados através de relações integradas e dinâmicas. Essa relação é claramente percebida por essas comunidades locais, as quais conseguem descrever uma série de processos geomorfológicos de maneira coerente e detalhada. Deste modo, o principal objetivo deste trabalho é apontar que o conhecimento etnogeomorfológico que as comunidades locais possuem encontra-se interligado aos demais elementos da paisagem, revelando assim que esses saberes são

\footnotetext{
${ }^{1}$ Vanessa Martins Lopes, Mestranda do Prograna de Pós-Graduação em Geografia, Universidade Federal de Pernambuco, Recife PE, Brasil.

${ }^{2}$ Simone Cardoso Ribeiro, Professora Adjunta do Departamento de Geociências/Laboratório de Geomorfologia e PedologiaGeoPed, Universidade Regional do Cariri, Crato-CE,Brasil
} 
amplos e integrados, se expandindo muito além dos conhecimentos geomorfológicos propriamente ditos, delineando assim a relação entre Etnogeomorfologia e Paisagem.

\section{METODOLOGIA}

Para a realização deste trabalho foi feita uma análise acerca dos conceitos de Etnogeomorfologia e de Paisagem. A discussão é movida com base nos resultados dos trabalhos etnogeomorfológicos realizados no Brasil por Ribeiro (2012) e Lopes (2014) já que através deles foi possível chegar às presentes conclusões acerca da relação entre Etnogeomorfologia e Paisagem.

\section{RESULTADOS E DISCUSSÃO}

Por meio da análise dos resultados observados nas pesquisas de Ribeiro (2012) e posteriormente Lopes (2014), tornou-se clara a amplitude do conhecimento que as comunidades locais - nos casos em questão, de produtores rurais do sertão nordestino- possuem acerca do relevo e da dinâmica ambiental. Abordaremos a seguir, de maneira sintética, os conceitos de Etnogeomorfologia e Paisagem, fazendo posteriormente uma discussão sobre a inter-relação destes dois conceitos.

\section{O conceito de Etnogeomorfologia}

Em sua evolução cientifica, a geomorfologia tem inserido ao longo do tempo, o papel da sociedade na modelagem e dinâmica geomorfológica, ultrapassando as barreiras de uma análise puramente naturalista. No entanto, as análises em sua maioria tem sido direcionadas às modificações antrópicas e seus impactos sobre os processos geomórficos. Estudos sobre os conhecimentos tradicionais (ou seja, pautados na cultura local) sobre formas e processos geomorfológicos e a utilização desse conhecimento no manejo geomorfológico, geralmente não tem sido observados. A escassez desse tipo de análise ocasiona não raramente, resultados negativos no manejo de formas e processos geomorfológicos.

Gregory (2006) destaca em seu estudo sobre a influência humana na mudança de canais fluviais, que a cultura não é instantaneamente considerada pelos geomorfólogos. Infelizmente isso não ocorre, embora os benefícios de uma abordagem pautada também numa perspectiva cultural devam surgir a partir de uma maior compreensão de como a percepção do papel humano muda os canais fluviais (e também outros sistemas geomorfológicos) ao longo do espaço e do tempo. 
Neste âmbito, a Etnogeomorfologia surge como uma nova abordagem que tem como um de seus objetivos incluir e compreender o papel do homem como um agente cultural ativo e extremamente importante dentro do sistema geomorfológico. Ela irá resgatar os valores das culturas locais sobre o relevo, pautando-se sob a ótica do entendimento e práticas de uso e manejo que essas comunidades exercem sobre a paisagem geomorfológica de que fazem parte, dando grande ênfase também aos processos geomórficos atuantes ali.

A Etnogeomorfologia é um campo novo de investigação na ciência geográfica. A referência mais antiga do tema no Brasil é encontrada nos anais do VI Simpósio Nacional de Geomorfologia/ Regional Conference on Geomorphology, ocorrido em 2006 em Goiana/GO intitulado Etnogeomorfologia: aplicações e perspectivas sob a autoria de Nunes Júnior, et.al.. O trabalho dos autores é conciso, e não foram encontrados trabalhos posteriores dando continuidade ao tema.

O único trabalho mais aprofundado encontrado na literatura brasileira é o de Ribeiro (2012) em sua tese de doutorado Etnogeomorfologia Sertaneja: proposta metodológica para a classificação das paisagens da sub-bacia do rio Salgado/CE. A autora desenvolveu uma abordagem metodológica no âmbito da Etnogeomorfologia "Sertaneja", já que o foco eram as comunidades de produtores rurais do sertão nordestino na mesorregião Sul Cearense, propondo uma classificação das paisagens analisadas.

No âmbito internacional, encontramos o trabalho de Wilcock (2011) entitulado Living Landscapes: 'Ethnogeomorphology' as an ethical frame of communication in environmental decision-making. Seu trabalho move uma discussão a partir de uma abordagem inclusiva na gestão de recursos naturais, respeitando as diferentes visões de mundo, e explorando formas de pensar sobre as paisagens físicas e culturais. No entanto, apesar de usar o termo "etnogeomorfologia" a autora volta a sua ênfase muito mais para a paisagem, sendo esta considerada como uma conexão entre as pessoas, o local e os recursos naturais.

$\mathrm{Na}$ literatura internacional podemos encontrar alguns autores que estão buscando novas abordagens, sendo estas similares à proposta da Etnogeomorfologia. Ashmore (2015) por exemplo, propôs o termo Sociogeomorpholgy para lidar com a co-evolução de sistemas explicitamente humanos e naturais. Segundo ele, este enquadramento distingue-se da "antropogeomorfologia", em que a análise tende a focar no impacto humano sobre um sistema "natural" ou em seres humanos como agentes emergentes em um sistema físico cujo papel pode ser externalizado ao ponto de ser uma nova fase na evolução do planeta. O próprio autor reconhece a similaridade com a Etnogeomorfologia quando afirma que esta abordagem "mais social" também pode se conectar a enquadramentos mais radicais de geomorfologia, como a "etno-geomorfologia" proposta recentemente por Wilcock et. al. (2013). 
No Brasil, alguns autores fazem menção a etnogeomorfologia, sem necessariamente usar o termo. Meireles (2014) em seu estudo sobre os impactos geoambientais relacionados à dinâmica geomorfológica na zona costeira cearense, ao descrever os impactos decorrentes da pressão antrópica associada à expulsão das comunidades locais, afirma que grande parte dos processos que caracterizam tais impactos, foram descritos por meio do conhecimento das comunidades tradicionais locais, os quais considera como ponto de partida para a formulação de preceitos científicos e denomina de "Geomorfologia Social".

Levando em consideração que elementos físicos da paisagem não estão dissociados das dinâmicas socioculturais locais, pois são direta ou indiretamente influenciados por elas, muitas formas de relevo e paisagens "impactadas" e "restauradas" pelo ser humano podem ser vistas como manifestações híbridas (co-produções) de natureza e cultura (sócio-natureza) (ASHMORE, 2015).

Sinteticamente dentro dessa perspectiva, podemos definir a Etnogeomorfologia como uma ciência firmada na interface entre ciências naturais e sociais, que estuda o conhecimento que uma comunidade tem acerca das formas e processos geomorfológicos, levando em consideração os saberes sobre a natureza e os valores da cultura e tradição locais. Ela pode ser considerada como uma ciência coirmã da Etnopedologia, sendo ambas intrinsecamente relacionadas à Etnoecologia (RIBEIRO, 2012).

As taxonomias e classificações geomorfológicas que as comunidades locais possuem para as formas e processos geomórficos exógenos são elementos muito importantes para o estudo etnogeomorfológico. A respeito dessas classificações, segundo Duvall (2008 apud TOLEDO; BARRERA-BASSOLS, 2009) há muitos exemplos sobre os termos utilizados pelos povos tradicionais para distinguir e nomear grandes estruturas geomorfológicas, já que praticamente toda cultura possui termos para designar os principais acidentes de seu espaço terrestre ou aquático.

Assim a investigação etnogeomorfológica pode ser usada para fornecer um quadro para o diálogo, que pode situar diferentes saberes em efetivo, mas que certamente nem sempre são consensuais. Além disso, ela possibilita vias de comunicação que promovem e reforçam as sinergias entre a geografia humana e física, colaborando para reconhecer paisagens como entidades simultaneamente geomorfológicas e culturais (WILCOCK et.al., 2013).

\section{$O$ conceito de paisagem}

A visão sistêmica representa um importante marco para a Geografia. A partir dela se desenvolveu a sistematização e integração do meio ambiente com elementos, conexões e processos como um potencial a ser utilizado pelo homem (TROPPMAIR; GALINA, 2006). 
Dentro dessa perspectiva se destaca o conceito de Geossistema, onde Sotchava foi o primeiro a utilizar o termo. Segundo Troppmair e Galina (2006), foi ele que trouxe e aplicou a visão sistêmica para a Ciência Geográfica, tornando-a desta forma competitiva e em posição equitativa com as demais ciências. Sotchava em sua obra $O$ estudo dos geossistemas discorre sobre a importância prática do Geossistema:

O impacto do homem na natureza, as questões de preservação e optimização do ambiente
natural, a utilização racional dos recursos naturais, cuidados com as paisagens culturais e, por
fim, todos os estudos em torno do fator antropogênico na ciência da paisagem são problemas
que, tomados em seu conjunto, compõem um círculo completo de tarefas sobre as quais as
atenções da sociedade contemporânea se acham focalizadas, pois todos estão assustados pela
deterioração do ambiente do homem e com a existência de lugares afetados por crises. Esses
problemas ultrapassam de muito o campo geográfico; o estudo de geossistemas tem,
entretanto, relaçãa direta com os seus vários setores (1977, p. 42).

Sotchava (1977, p.47) afirma que o estudo geossistêmico “em relação a muitos de seus aspectos, faz apelo direto à colaboração do homem com a natureza, sobretudo no tocante àqueles referentes à dinâmica dos geossistemas, suas peculiaridades funcionais, potencial de outros recursos e outros problemas".

A abordagem sistêmica e a paisagem estão intimamente interligadas. A estrutura, as interrelações e a dinâmica que ocorrem em determinada área compondo um Geossistema, dão a feição, a fisionomia daquele espaço, que é a própria paisagem vista como sistema, como unidade real e integrada. Deste modo, a ideia de paisagem não se refere apenas ao que é observável, pois o conhecimento dos fenômenos e processos menos visíveis são essenciais para se interpretá-la de forma integral (CONTI, 2014; TROPPMAIR; GALINA, 2006).

A paisagem é um fato concreto, um conceito fundamental para a Geografia, pois ela é a fisionomia do próprio Geossistema (TROPPMAIR; GALINA, 2006). Ela se constitui em um ambiente ativo, dinâmico, complexo e integrado, que se encontra em constante processo evolutivo. Os elementos que a constituem, igualmente, não se encontram desconectados, e mantém sempre uma relação de diálogo e interdependência entre si. Sobre esse assunto, Bertrand (2004, p. 141) relata que:

A paisagem não é a simples adição de elementos geográficos disparatados. É, numa determinada porção do espaço, o resultado da combinação dinâmica, portanto instável, de elementos físicos, biológicos e antrópicos que, reagindo dialeticamente uns sobre os outros, fazem da paisagem um conjunto único e indissociável, em perpétua evolução.

O autor faz questão de destacar que o foco deve ser a paisagem em sua totalidade, de modo a integrar toda a relevância da ação antrópica sobre o ambiente. Nesse sentido, a abordagem sistêmica entende a paisagem como um todo integrado, onde o homem é parte constituinte essencial. É importante destacar como bem observou Schier (2003) que Bertrand não privilegia nem a esfera natural nem a humana. 
No entanto, é importante reiterar além da paisagem numa concepção sistêmica e integrada, a paisagem dentro de uma perspectiva cultural. Destaca-se nesse sentido um dos precursores da ideia, Carl Sauer, que considerou a paisagem, como fruto das práticas culturais que ocorreram ao longo do tempo graças à ação humana sobre o ambiente.

Sauer (2007 apud RIBEIRO, 2012, p. 71) também reconhece o homem como o último agente que modifica a superfície da Terra, devendo ser considerado como um agente geomorfológico, já que vem alterando cada vez mais as condições de denudação e de colmotação da superfície terrestre.

Dentro da perspectiva de paisagem cultural, Cabral (2000, p.38) destaca que "a paisagem não pode ser considerada isoladamente e nem ser dissociada do sujeito que a vivencia." Logo, reiteramos a ideia de Bertrand de considerar o homem na análise, enfatizando que ele além de agente transformador, é também um agente perceptivo dela.

\section{A relação entre Etnogeomorfologia e Paisagem}

Cabral (2000) defende que as paisagens, assim como espaços e lugares, na medida em que são experienciadas diretamente como atributos do mundo vivido, constituem as bases fenomenológicas da realidade geográfica e representam sentido dos nossos envolvimentos com o mundo. Do mesmo modo, Wilcock et.al. (2013) ressaltam que a Etnogeomorfologia se baseia numa conexão. Conexão entre seres humanos e paisagens físicas. Estas paisagens biofísicas/culturais são inscritas pela sobreposição de histórias, histórias que representam experiencias vividas e implicam numa tempestade perfeita de relações entre paisagens e aqueles que a habitam e estão contidos dentro nela. Em tese, as paisagens são vistas como entidades (vivas) dinâmicas e sensíveis que necessitam de uma voz para si próprias.

O trabalho de Ribeiro (2012) sobre Etnogeomorfologia Sertaneja deu-se com produtores rurais de quatro locais distintos da sub-bacia do rio Salgado, mesorregião sul do Ceará, geograficamente localizada no sertão do nordeste brasileiro, embora tenha características diferenciadas em virtude da influência da Chapada do Araripe.

O resultado obtido pela autora foi a descoberta de uma série de nomenclaturas (bastante similares) utilizadas pelos produtores rurais para as formas de relevo e cicatrizes erosivas. Além disso, os processos morfoesculturadores foram por eles muito bem identificados e compreendidos. Foram reconhecidas a erosão laminar e concentrada, movimentos gravitacionais de massa, assoreamento e outros processos causados pela dinâmica de fluxo sedimentar na esculturação geomorfológica e pela influência da ação antrópica na estabilidade geomorfológica. Além disso, foi 
observado também um vasto conhecimento etnopedológico relacionado à classificação pedológica, a propriedades do solo e fertilidade relacionados a distribuição dos mesmos nos diferentes tipos de relevo das áreas de estudo em questão.

Também foi desenvolvido trabalho sobre Etnogeomorfologia Sertaneja por Lopes (2014) sob a orientação de Ribeiro, sendo o mesmo executado em duas novas localidades da mesma região estudada por Ribeiro (2012). Em tal trabalho, a autora constatou que a paisagem é entendida pelos sertanejos, como elemento heterogêneo e diferenciado, segundo eles pelo tipo de solo, morfologia e a altitude do terreno. As nomenclaturas para as formas de relevo e cicatrizes geomorfológicas oriundas de processos erosivos apesar de diversas se mostraram bastante similares entre as comunidades estudadas, pois por vezes havia mais de um nome para uma forma geomorfológica, no entanto um destes ou ambos, se repetiam para a mesma forma na outra comunidade.

À propósito, no que se refere aos processos esculturadores do relevo, a visão que os produtores rurais sertanejos demonstraram ter é de caráter integrativo, pois relacionam tais processos aos fatores controladores da erosão pluvial como erosividade da chuva, erodibilidade do solo, características das encostas e tipo de cobertura vegetal. Além disso, reconhecem dentro dos processos geomórficos, as fases de desgaste, transporte e deposição de sedimentos na paisagem, bem como a visão de que tais processos são dinâmicos, evolutivos e influenciados pela ação antrópica no uso e manejo das terras, que deste modo também é visto por eles como um fator controlador da erosão.

Demonstraram ainda amplo conhecimento etnopedológico através da classificação de solos, descrição de sua localização no terreno bem como de sua estrutura e fertilidade. Conhecimentos sobre tipos de vegetação, dinâmica climática e as chamadas "experiências"e sobre as possibilidades de chuva no sertão, através da interpretação de "sinais" da natureza que revelam se haverá ou não um "bom inverno", também foram identificados.

Comprovamos então, através dos resultados obtidos nos trabalhos etnogeomorfológicos já desenvolvidos, que o conhecimento que as comunidades tradicionais detêm não se limita a um único aspecto sobre a natureza, no caso em questão sobre o relevo, mas ao contrário se mostra bastante amplo, integrado e detalhado. Tais conhecimentos não podem ser negligenciados, mas devem ser foco de análise a fim de serem reconhecidos como essencialmente importantes na gestão ambiental territorial.

A respeito da visão integrada da paisagem desses povos, Duvall (2008) em um estudo sobre a classificação dos recursos do ambiente biofísico dos agricultores de Maninka no sudoeste de Mali, afirma que embora as classificações separadas de topografia, hidrologia, vegetação, microclima e 
características de superfície do solo sejam importantes, a maioria dos agricultores a consideram de maneira integrada quando estão classificando ou descrevendo partes da paisagem.

Para este autor a compreensão de conceitos locais culturalmente específicos é crucial para a compreensão de como as pessoas percebem paisagens, e não apenas determinadas categorias das características físicas geográficas. No entanto, com demasiada frequência, etnoecólogos tem se concentrado em recursos, como o solo por exemplo, e não em paisagens. Além disso, ele destaca que uma comunicação eficaz sobre geografia física exige muito mais do que simplesmente traduzir termos.

Assim, tradição cultural deve ser incluída na gestão ambiental e geomorfológica. Os geomorfólogos agora podem considerar as distinções culturais e considerá-las na construção de suas recomendações. No entanto, seja na etnogeomorfologia ou na sociogeomorfologia, isso não é algo normalmente familiar e confortável. Alguns podem discordar com esta mudança de posição filosófica, já que se trata de um repensar da natureza científica da geomorfologia, reformulando a sua posição com relação às paisagens que são por ela investigadas. No entanto esses esforços são necessários (ASHMORE, 2015; GREGORY, 2006).

A visão integrada de paisagem desses grupos nos leva a ideia de "etnopaisagem". Tal ideia reformula a concepção compartimentada da modernidade, onde a realidade é estudada em partes que se relacionam mas são, dentro da lógica moderna, analisados separadamente. A especialização do saber, que nasce com a Modernidade, trouxe seu aprofundamento, mas também trouxe boa parte da perda da visão de totalidade antes experimentada pelos pensadores e - ainda hoje - praticada por essas comunidades tradicionais.

\section{CONSIDERAÇÕES FINAIS}

A importância e riqueza do conhecimento etnogeomorfológico se revela a partir das histórias contadas, da explicação da dinâmica natural e da classificação ambiental e geomorfológica local, os quais são dotados de coerência e detalhes que são construídos através da observação e manejo do ambiente. A paisagem é vista por esses povos em sua totalidade integrativa, sendo essa visão fruto das experiências vividas com o ambiente da qual fazem parte. Essa ampla percepção comprova a racionalidade do conhecimento etnogeomorfológico e ambiental como um todo. Assim através da lente etnogeomorfológica podemos perceber que as paisagens, sobretudo geomorfológicas, são mais do que sistemas dinâmicos e integrados, são "etnopaisagens" que por serem vividas são dotadas de sentido e significado. 


\section{REFERÊNCIAS}

ASHMORE, P. Towards a sociogeomorphology of rivers, Geomorphology, 2015.

BERTRAND, G. Paisagem e Geografia Física Global. Esboço Metodológico. Tradução: Olga Cruz. Revista Raega, n. 8. Curitiba: 2004.

CABRAL, L. O. A paisagem enquanto fenômeno vivido. Geosul, v.15, n³0. Florianópolis: 2000.

CONTI, J. B. Geografia e Paisagem. Ciência e Natura, v. 36, Ed. Especial. Santa Maria: 2014.

DUVALL, C.S. Classifying physical geographic features: the case of Maninka farmers in southwestern Mali. Geografiska Annaler: Series B, Human Geography 90, 2008.

GREGORY, K.J. The human role in changing river channels. Geomorphology 79, 2006.

LOPES, V. M. Etnogeomorfologia Sertaneja: análise comparativa entre os conhecimentos tradicionais dos produtores rurais familiares sobre os processos morfoesculturadores e sua utilização no uso e manejo do solo nos municípios do Crato e Barbalha/CE. Relatório de Pesquisa. Programa Institucional de Bolsas de Iniciação Científica - PIBIC/URCA, 2014. 64p.

MEIRELES, A. J. A. Dinâmica Geoambiental Da Zona Costeira. Nota de aula - 2014.2 Programa de Pós-Graduação em Geografia, Universidade Federal do Ceará, 2014, 305p.

NUNES JR, E; BARROS GOES, M. H. de; AGUILAR, R. A. dos S.; GUERREIRO, M. Etnogeomorfologia: aplicação e perspectivas. In: VI Simpósio Nacional de GeomorfologiaSINAGEO; Regional Conference on Geomorphology, Goiânia/GO 2006. Disponível em: http://www.labogef.iesa.ufg.br/links/sinageo/articles/507.pdf Acesso em: 02/06/2016

RIBEIRO, S. C. Etnogeomorfologia Sertaneja: proposta metodológica para a classificação das paisagens da sub-bacia do rio Salgado/CE. Tese de doutorado apresentada ao Programa de Pós Graduação em Geografia da Universidade Federal do Rio de Janeiro, 2012. 278p.

SCHIER, Raul Alfredo. Trajetórias do conceito de paisagem na Geografia. Revista Raega, n. 7. Curitiba: 2003.

SOTCHAVA, V. B. O estudo de geossistemas. Tradução: Carlos Augusto Figueiredo Monteiro e Dora de Amarante Romariz. USP/Instituto de Geografia. São Paulo: 1977.

TOLEDO, V. M.; BARRERA-BASSOLS, N. A Etnoecologia: uma ciência pós-normal que estuda as sabedorias tradicionais. Desenvolvimento e Meio Ambiente, n.20. Curitiba: 2009.

TROPPMAIR, H.; GALINA, M. H. Geossistemas. Mercator, ano 05, nº 10. Fortaleza: 2006.

WILCOCK, D. A. Living Landscapes: 'Ethnogeomorphology' as an ethical frame of communication in environmental decision-making. Tese de Doutorado apresentada ao Graduate Program in Environmental Studies/York University, 2011.

WILCOCK, D.; BRIERLEY, G.; HOWITT, R. Ethnogeomorphology. Progress in Physical Geography. Sydney: 2013.

\section{AGRADECIMENTOS}

Ao Conselho Nacional de Desenvolvimento Científico e Tecnológico - CNPQ, pelo auxílio no desenvolvimento deste trabalho em forma de bolsa de estudo.

Recebido em: 14/08/2016

Aceito para publicação em: 01/10/2016 